\title{
Health care professionals dealing with hemophilia: insights from the international qualitative study of the HERO initiative
}

This article was published in the following Dove Press journal:

Journal of Multidisciplinary Healthcare

\author{
Silvia Potì ${ }^{\prime}$ \\ Laura Palareti ${ }^{1}$ \\ Frederica RMY Cassis ${ }^{2}$ \\ Sonia Brondi ${ }^{1}$ \\ 'Department of Education Studies \\ "Giovanni Maria Bertin", University of \\ Bologna, 40126 Bologna, Italy; ${ }^{2}$ Faculty of \\ Medicine Clinics Hospital, University of São \\ Paulo, São Paulo, SP, 05403-000, Brazil
}

Background: Assessing the viewpoints of health care professionals concerning their work with chronic patients is a relatively new research topic, widely overlooked in the literature. However, understanding their subjective work experience is highly relevant for identifying problems and perceived resources, enhancing health service organisation, improving relationships or communication with patients, and maintaining well-being.

Purpose and method: Qualitative data from the "Haemophilia Experience, Results and Opportunities" Initiative - a research program aimed at investigating the psychosocial aspects of hemophilia - were used to evaluate the experiences of 62 professionals from seven countries around the world. Semi-structured interviews were submitted to thematic analysis of elementary contexts with the aid of T-Lab software.

Results: Five dominant themes emerged, identifying the main challenges that professionals have to deal with in their everyday work practice: caring for impaired adult patients; handling policies and stakeholders; providing counselling on diagnosis and reproductive choices; considering the role of family dynamics; coping with adolescent patients.

Conclusion: The outcomes of the study provide an opportunity to develop the area of the non-technical skills in the core curriculum of those who work with chronic illnesses by focusing on cross-professional competences and by improving a comprehensive care model for hemophilia patients.

Keywords: health care professionals, subjective experience, chronic illness, hemophilia, cross-cultural

\section{Introduction}

Understanding the subjective work experience of health care professionals (HCPs) has profound implications at individual, relational, organisational and societal levels. This is even more impelling if we shift our focus from acute to chronic illness: taking care of patients with persistent or long-lasting conditions puts a strain on maintaining HCPs' well-being, requires the involvement of specific non-technical skills (in addition to medical skills), requires different HCPs to work together extensively on a long-term basis, and implies the existence of health care services ensuring such continuity.

However, the viewpoint of HCPs working either with acute or chronic patients has been little examined by medical researchers and social scientists. Few studies have investigated HCPs' emotions, cognitive beliefs, attitudes, values and language, ${ }^{1}$ which are all factors that greatly affect the quality of their relationships with patients, caregivers and colleagues, as well as the quality of their work.
Department of Education Studies

"Giovanni Maria Bertin", Alma Mater

Studiorum - University of Bologna, Via

Filippo Re, Bologna 640126, Italy

Tel +39051 2091620

Email silviapoti@gmail.com 
This study aims to contribute to bridging this gap, by focusing on a specific chronic illness, ie, hemophilia, a rare bleeding disorder. For this purpose, a psychosocial approach can help enter this debate: social psychology can offer useful insights in this direction thanks to its unique and multi-faceted level of explanation (ranging from intrapersonal to inter-personal, social and societal processes). ${ }^{2}$

In particular, at an intra-personal level, psychosocial literature has suggested that HCPs' well-being is correlated with a lower incidence of stress experiences, psycho-emotional difficulties, burnout incurrences, and professional identity threats, as well as with stronger motivation. $^{3}$

In parallel, at an inter-personal level, HCPs' well-being also helps to build quality relationships with patients, caregivers and colleagues. By contrast, HCPs may experience lack of control dealing with patients' noncompliance, ${ }^{4,5}$ or may have difficulties in communicating diagnosis and in managing family emotions. ${ }^{6,7}$

Moreover, at a social level, the representations of patients and caregivers, and the perceptions of everyday work practices are very important factors. The risk for HCPs is that of reducing their work commitment and effectiveness. ${ }^{89}$

Finally, at a societal level, HCPs' well-being is correlated with the good quality of care provided. Conversely, when HCPs experience some difficulties and social support is lacking, the performance of the entire health care system can be sub-optimum. ${ }^{8-10}$ Also, there can be some productivity pressures in health care financing, so that the health care system may be overburdened. ${ }^{11}$

Within this psychosocial framework, we examined the subjective experience of HCPs working with hemophilia. The objective of the study was two fold: on the one hand, it seeks to understand the common models that substantiate the work practices of different HCPs and to get an overview of the cognitive and affective meanings that characterise them; on the other hand, it seeks to explore how respondents' professional and social characteristics (country, medical speciality, years of experience, work in team) affect the representation of caring for patients and their families.

Before presenting the study in detail, we will first introduce hemophilia, its treatment and related psychosocial issues.

\section{Why hemophilia?}

Hemophilia is a rare inherited bleeding disorder linked with the $\mathrm{X}$ chromosome that affects only men, while women can be carriers. ${ }^{12}$ Hemophiliacs' bodies do not produce sufficient clotting factor VIII (Hemophilia A) or IX (Hemophilia B). This results in internal or external bleeding episodes, occurring spontaneously or following injuries, traumas and surgery, depending on the clinical severity. Repeated bleeding episodes, especially if they are not treated promptly, can cause long-term musculoskeletal problems and joint damage (eg, chronic synovitis, degenerative arthropathies and articular deformities); painful hemorrhages can also occur in internal soft tissues (eg, subcutaneous tissues, abdominal muscles, brain). ${ }^{13}$

Treatment consists in replacing the missing factor episodically or preventively: episodic use (on-demand treatment) involves infusions after traumas; preventive use (prophylactic treatment) involves infusions on a regular schedule. Both treatments can be performed at home, through self-infusions that can be learned by patients and family members at an early age, or in hospital environments, by medical staff. In particular, Haemophilia Treatment Centres (HTCs) are specialised health care centres capable of delivering adequate care. In accordance with the World Federation of Haemophilia (WFH)'s guidelines for the treatment of hemophilia and other blood clotting disorders, which promote the adoption of a comprehensive care model, HTCs bring together a multidisciplinary team of professionals experienced in the field of hemophilia (ie, including hematologists, geneticists, nurses, psychologists, social workers and dentists). ${ }^{14-16}$

Generally, treatment compliance is very high during the patients' childhood, when their parents take care of the infusions, and then declines during adolescence, when young patients become more independent, and have to cope with disclosure to classmates and friends, as well as with the limitations imposed by the disease, such as the impossibility to practice contact sports. ${ }^{17-19}$

Compared to the past, these days the life expectancy of hemophiliac patients has improved significantly; thanks to the greater number of therapeutic options and products developed by biomedical research and the pharmaceutical industry, if treated adequately, the patients' quality of life can be almost normal. On the contrary, in the Eighties, the average lifespan was shorter and the main cause of death was AIDS or hepatitis, as a consequence of infusions with blood infected with HIV or HCV viruses, respectively. However, there are still considerable variations between countries, due to the social, economic, political and 
cultural differences that influence the quantity, availability and type of treatments offered (which are very expensive as a whole).

While the psychosocial dimension of hemophilia has been extensively addressed with regard to the people affected (families and patients, especially during childhood), ${ }^{20,21}$ very few studies have been conducted with respect to the HCPs working in this field. The limited literature available, in particular, focuses on the risks of burnout related to having to take care of a chronic disease subject with many risks of complications and comorbidities. $^{22-24}$ In this regard, although specific data on hemophilia are not available, recent research has stressed that more than half of the physicians dealing with chronic disease and co-morbidities have experienced symptoms of burnout and a similar prevalence is also found among nurses. This rate varies widely depending on the medical specialty (eg, up to 300 percent increased odds of burnout among some specialites such as emergency medicine, which also concerns hemophilia treatment, as compared with other specialties) as well as on the career stage (25 percent more likely among midcareer physicians than early or late career). ${ }^{25}$

Hence, assuming that hemophilia treatment goes well beyond factor replacement therapy, the aim of this research was to lend a voice to the HCPs working in the hemophilia field, which is largely unheard of in the literature, by adopting a psychosocial and cross-cultural perspective.

\section{Material and methods}

To achieve the two objectives of this study, that are 1) to understand the common models and the subjective meanings that substantiate the work practices of HCPs and 2) to explore how respondents' socio-demographic and professional variables affect these representations, we have chosen a psychosocial qualitative methodology of textual analysis that allows to investigate the main themes shared by all participants, and how some chosen variables are associated with the emerging themes. This type of explorative bottom-up methodology has often been used in health psychology, proving to be a useful tool to grasp the multi-faceted accounts produced by different groups of respondents with the help of specific software for textual analysis. ${ }^{26}$ The software allows for data synthesis and a deeper understanding of the meanings expressed by participants, allowing inferences about the emotional and cognitive representations that are not easy to identify at an explicit semantic level. ${ }^{27,28}$
We analysed the accounts produced by different HCPs working with hemophiliac patients of different ages. The data were collected within a broader international and multidisciplinary research program, the Haemophilia Experience, Results and Opportunities (HERO) Initiative, aimed at understanding the psychosocial aspects of hemophilia from the perspective of patients, their caregivers and their HCPs. ${ }^{29,30,31}$

Qualitative textual data were submitted to the thematic analysis of elementary contexts with the support of T-Lab software. $^{32}$ Through this type of analysis, the researcher makes inferences about the lexical choices of the interviewees and how the pattern of the same keywords are combined across the narratives. The resulting themes can be considered latent shared themes, which can be influenced by the topics solicited by the interviewer, but do not correspond to them: a particular association of concepts/ words may in fact appear in response to different topics, so what emerges as a main theme will be the issue expressed via such an association. ${ }^{33}$

The study was based on 62 interviews with HCPs from seven countries, distributed as follows: 14 HCPs from countries with developing economies according to the latest UN classification (4 from Algeria and 10 from Brazil) and 48 HCPs from countries with developed economies ( 8 from France, 8 from Germany, 8 from Italy, 10 from the United Kingdom, and 14 from the United States of America). This variable was included to take into account potential differences emerging from the different resource settings and, consequently, from the diverse quantity, availability and type of treatments proposed, especially access to prophylaxis. ${ }^{34}$

Participants were physicians (mainly haematologists) $(n=31)$, while other respondents included nurses $(n=16)$, physiotherapists $(n=9)$, social workers $(n=3)$, and psychologists $(n=3)$. Fifty-five of them worked in a multidisciplinary team, while 7 did not; 26 worked for more than 10 years, 8 for 5-10 years, 1 for less than 5 years, while for 27 this label was unassigned. These variables were selected to consider potential differences related to diverse professional roles and responsibilities as well as related to diverse career stages, which, as mentioned above, together with the medical specialty is predictor of well-being among HCPs dealing with chronic disease and co-morbidity. ${ }^{25}$

The HERO International Advisory Board and a specialist Health care Research Agency managed participant recruitment in each country. They contacted the 
participants in the HTC or in the hospital where they work by sending them a letter presenting the research objectives, and inviting them to participate in a semi-structured anonymous interview process.

Individual face-to-face interviews were performed by specialists of the Health care Research Agency. The interviews took place at the workplace in a quiet and comfortable room and lasted about 60 mins each. At the end of the interviews, participants were asked to complete a short questionnaire to collect professional and social information. All interviews were audio-recorded and transcribed. The Health Research Agency also translated the transcriptions of the interviews into English and texts were given to the HERO International Advisory Board.

Participation was voluntary and written informed consent was obtained from all individual participants involved. All procedures were in accordance with the ethical standards of the institutional and/or national research committee of each country and with the 1964 Helsinki Declaration and its later amendments or comparable ethical standards.

The interviewer encouraged participants to talk about their own personal experiences through non-directive prompts and a list of open-ended questions. The interview grid was prepared by the Health Research Agency and supervised by one of the authors of this article. After an introductory warm-up, in which HCPs were asked to introduce themselves by answering some questions about their role and responsibilities, involvement in multidisciplinary teams, reasons underlying career choice, work satisfaction and frustration, the following topics were addressed: managing the early diagnosis of hemophilia; caring for a child growing up with hemophilia; living with hemophilia now; treatment of hemophilia, support provided; future aspirations. For each topic, the work practices, as well as the positive and negative experiences, were explored.

\section{Data analysis}

Operationally, we first collected the interviews in a single corpus text and omitted the interviewer's questions, because the software is sentitive to the occurrence of the words. Each anonymous interview was then labelled according to the set of professional and social variables selected for the study: country (Algeria, Brazil, France, Germany, Italy, UK, and USA); medical speciality (physician, nurse, physiotherapist, psychologist, social worker); years of experience $(<5,5-10,>10)$; teamwork (yes, no).
Finally, empty words were removed (eg, articles, conjunctions, prepositions); only the retained keywords were disambiguated (ie, if a word had more of one meaning) and then lemmatised. At the end of this process, the vocabulary subjected to the thematic analysis in our case was composed of 5,000 keywords.

The analysis first allows for the identification of the significant clusters, ie, the core themes shared by participants. Each cluster consists of a set of Elementary Context Units (ECUs), ie, sentences, or short texts characterised by the same patterns of keywords, and is described through lemmatised keywords (or, in some case, by modalities of variables), which co-occur in the same portions of text (ECU), ranked according to the decreasing value of $\chi^{2.32}$ Each cluster has a different weight according to the percentage of text (sentences) that includes with respect to the whole amount of ECUs, and is therefore a theme more or less representative for the participants.

Clusters are placed in a global matrix of meanings that represent the whole text. The software provides a graphic representation of the whole universe of meanings evoked by the participants. It is a factorial space, defined by a number of bipolar factors, characterised by opposite processes of meaning. Factors are the latent dimensions of meanings in the textual corpus. Different groups of keywords, ranked according to V-test, contribute to the definition of each polarity and allow their interpretation.

Within this factorial space, both clusters and modalities of the variables are placed. Looking at the graphic, interpretations about the themes according to their positioning in the space can be advanced. Moreover, observing the positioning of the modalities of the variables, it is possible to suggest which themes are particularly close to (and relevant for) particular sub-groups of participants.

Clusters and factors are then obtained by a statistical analysis of the multiple correspondences between the individual lemmas and text segments as well as a subsequent hierarchical factor analysis applying the Ward technique. ${ }^{35}$

All the authors analyzed the results of the statistical outputs, redefining the interpretations and labeling each cluster and each factor's polarity.

\section{Results}

Five core themes emerged from the cluster analysis. We will discuss each theme in detail and in order of weight, as well as the aspects of hemophilia that directly affect the HCP's experience, both from a cognitive and affective viewpoint. Tables $1-6$ report the cluster weight, the typical 
Table I Number of sentences forming each cluster and percentage weight compared to the total

\begin{tabular}{|c|c|c|}
\hline Clusters & $\begin{array}{l}\text { Number of sentences (Elementary Context } \\
\text { Units, ECUs) that form the cluster out of a total } \\
\text { of } 3,954 \text { classified }\end{array}$ & Weight \\
\hline N.I “Caring for impaired adult patients" & 1,010 sentences & $25.54 \%$ \\
\hline N.2 "Handling policies, resources, and stakeholders" & 592 sentences & $24.08 \%$ \\
\hline N.3"Providing counselling on diagnosis and reproductive choices" & 724 sentences & $18.31 \%$ \\
\hline N.4"Considering the role of family dynamics" & 689 sentences & $17.43 \%$ \\
\hline N.5"Coping with adolescent patients" & 579 sentences & $14.64 \%$ \\
\hline
\end{tabular}

lemmatised keywords for each theme, according to their $\chi^{2}$ values, and some illustrative excerpts in which they cooccur (ECUs).

\section{Theme I: caring for impaired adult patients}

In the first theme, the most representative, the burden related to the subjective work experience appears.

Interviewed HCPs evoked the potential complications of the illness and its care: the arthropathies (or other joint damages), the development of inhibitors, the transfusions of contaminated blood that transmitted HCV and HIV in the past (and, more generally, the risk of infected plasma), the lack of treatment compliance, the management of hospitalisation and rehabilitation periods. The respondents also cited the missed opportunity to produce long-lasting improvements for the patient's life. The work experience shows all the problems associated with the illness and the care. In this regard, HCPs have to face several difficulties, struggles and challenges. Although these aspects are well-known from a medical viewpoint, the psychosocial impact pointed toward intense feelings of helplessness and frustration. In particular, the participants talked about the dynamics of burnout that such cognitive and affective categorisation may cause. HCPs also evoked the prejudice that society has towards the patient with hemophilia and (mis)fortune as the root-cause of all the problems.

Moreover, on the one hand, the adult is considered only as a patient, a body to treat, a disempowered carrier of limitations, dysfunctions and disabilities without any resource; on the other hand, the doctor-patient relationship seems to be very close-knit, as a result of identification and mirroring processes, without the mediation of associations, caregivers, or friends, and without prospects of development.
This is a theme that has already been stressed in the scientific literature and described as a threat to the HCPs' wellbeing. ${ }^{36-40}$

It is worth noting that this theme seems to be transversal to all participants, regardless of the considered social and professional variables: no sub-group of participants in relation to their country, medical speciality, experience in the field or customary to work in a team significantly contributes to the definition of this cluster.

\section{Theme 2: handling policies, resources, and stakeholders}

The second theme indicates the need for HCPs to deal with economic issues and have more resources to accomplish better work (the first keywords in this cluster, according to $\chi^{2}$, are "money" and "improve").

Central to this theme is the idea of a multidisciplinary model of care: the importance of a team, a specialised staff composed of different professionals, and colleagues who work co-ordinately at the same health care facility is mentioned. However, while enlarging the perspective and considering the hemophilia care as teamwork carried out by different actors, patients and their needs seem to be overlooked, since only the economic and social costs are discussed. All the involved stakeholders are evoked, including drugs companies and pharmaceutical industries, with the exception of the associations of patients (which are rather widespread and active organisations) and their families. According to the respondents, this care model is affected by administrative issues, such as local policies, governments, bureaucratic constraints, organisational matters, public health services or private systems. The word "salary" appears, also when referring to professional economic needs.

In addition to economic and human resources, HCPs require more time to ensure an adequate quality of care. However, this theme is a mere neutral description of policies 
Table 2 Keywords in order of $\chi^{2}$ and examples of sentences of the cluster no. I

\begin{tabular}{|c|c|c|}
\hline \multicolumn{3}{|c|}{ Keywords of the cluster (in order of $\chi^{2}$ ) } \\
\hline $\begin{array}{l}\text { work (83.93), } \\
\text { job (24.23), } \\
\text { change (24.0I), } \\
\text { joint (22.56), } \\
\text { surgery (I8.99), } \\
\text { chronic (I7.49), } \\
\text { blood (I7.48), } \\
\text { adult (I5.70), } \\
\text { transfusion (I5.48), } \\
\text { problem (I5.47), } \\
\text { disease (I4.97), } \\
\text { population (I3.68), } \\
\text { rehabilitation (I3.65), } \\
\text { diary (I3.34), } \\
\text { deal (I2.53), } \\
\text { health (I2.30), } \\
\text { today (II.94), } \\
\text { hospital (II.90), } \\
\text { small (II.87), } \\
\text { face (I I.87), } \\
\text { employment (II.53), } \\
\text { frustrate (II.27), } \\
\text { common (II } .08) \text {, } \\
\text { difficult (I0.67), } \\
\text { lot (I0.20), } \\
\text { organize (I0.04), }\end{array}$ & 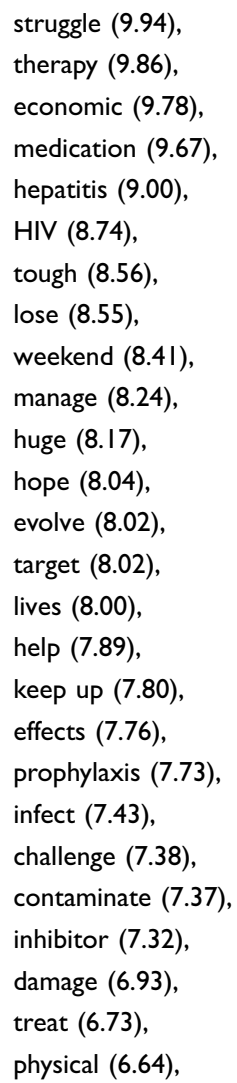 & $\begin{array}{l}\text { drug (6.20), } \\
\text { plasma (6.II), } \\
\text { patient (5.82), } \\
\text { lucky (5.68), } \\
\text { reward (5.62), } \\
\text { occur (5.62), } \\
\text { autonomy (5.49), } \\
\text { burnout (5.4I), } \\
\text { break (5.4I), } \\
\text { prejudice (5.34), } \\
\text { dysfunction (5.I4), } \\
\text { well-being (5.I4), } \\
\text { adverse (5.I4), } \\
\text { arthropathy (5.I4), } \\
\text { fight (4.98), } \\
\text { unable (4.87), } \\
\text { resolve (4.87), } \\
\text { similarity (4.87), } \\
\text { interfere (4.4I), } \\
\text { recombinant (4.4I), } \\
\text { preparation (4.27), } \\
\text { hard (4.I5), } \\
\text { day to day (4.I5), } \\
\text { adhere (4.06), } \\
\text { limit (3.85) }\end{array}$ \\
\hline \multicolumn{3}{|c|}{ Examples of sentences of the cluster (ECUs, Elementary Context Units) } \\
\hline \multicolumn{3}{|c|}{$\begin{array}{l}\text { «They have got an inhibitor, they have got really serious bleedings, they are crippled, and they have kind of gotten into a more hopeless space in } \\
\text { their lives. I just think of a guy who is in and out of the hospital all the time because of horrible chronic pain and arthritic joints and working with } \\
\text { him in a fairly ongoing way to try to help him.» (USA, social worker, in team, level of experience 3). } \\
\text { «The problem is the psychological side of it. The adults professionally cannot do some jobs, like maintenance, lift heavy weights. There are a lot of } \\
\text { jobs they cannot do because of their existing handicap or their damaged joints » (France, nurse, in team, level of experience 2). } \\
\text { «Many patients are HIV positive, many have hepatitis B and they got it when they used to get a lot of blood transfusions. So you have to raise these } \\
\text { issues and work them, too » (Brazil, nurse, in team, level of experience 3) } \\
\text { « I get a lot of satisfaction from my work: I follow my patients from the very beginning and I can see them growing up, getting married, the adults } \\
\text { growing old» (Italy, haematologist, in team, level of experience 2) }\end{array}$} \\
\hline
\end{tabular}

and practices, with no reference to feelings or personal involvement with patients.

This theme is specifically stressed by some sub-groups of participants: HCPs from USA, social workers and the most experienced professionals especially contribute to the construction of this cluster.

\section{Theme 3: providing counselling on diagnosis and reproductive choices}

The most relevant issues in the third theme are diagnosis and family history, linked to the problem of the inheritance of the illness. Several keywords with high $\chi^{2}$ values are related to communication and listening skills ("speak", "question", “explain”, “inform”, “answer", “discuss”, "listen", "hear", "know"). HCPs have to make understandable the diagnosis adopting two alternative strategies: the most cited strategy is the "step by step" one, which is preferred to the "all at once" one. They also have to communicate risks and be prepared to dispel any doubts.

HCPs are actively involved in the doctor-patient relationship; their role is to manage the quality of the relationship with patients, dealing with the emotional 
Table 3 Keywords in order of $\chi^{2}$ and examples of sentences of the cluster no. 2

\begin{tabular}{|c|c|c|}
\hline \multicolumn{3}{|c|}{ Keywords of the cluster (in order of $\chi^{2}$ ) } \\
\hline $\begin{array}{l}\text { money (I54.22), } \\
\text { improve (108.05), } \\
\text { orthopaedic (77.89), } \\
\text { physiotherapist (75.38), } \\
\text { access (67.57), } \\
\text { resource (66.40), } \\
\text { quality of life (66.0I), } \\
\text { colleague (6I,94), } \\
\text { specialize (6I.75), } \\
\text { compare (60.69), } \\
\text { expensive (60.6I), } \\
\text { fund (59.35), } \\
\text { haematologist (58.99), } \\
\text { social worker (57.68), } \\
\text { spend (57.38), } \\
\text { team (55.57), } \\
\text { coordinate (52.|4), } \\
\text { nurse (5I.87), } \\
\text { service (49.34), } \\
\text { reference (48.99), } \\
\text { dental (47.98), } \\
\text { work (45.18), } \\
\text { medical (42.23), } \\
\text { staff (4I.96), } \\
\text { right (4I.76), } \\
\text { nurse coordinator (4I.55), }\end{array}$ & $\begin{array}{l}\text { physician (38.79), } \\
\text { cost (38.09), } \\
\text { insurance (37.45), } \\
\text { prescribe (37.10), } \\
\text { Centre (36.52), } \\
\text { provide (32.63), } \\
\text { human (3I.44), } \\
\text { public (29.19), } \\
\text { assistance (29.19), } \\
\text { quality (28.72), } \\
\text { therapist (28.72), } \\
\text { community (28.52), } \\
\text { invest (26.97), } \\
\text { financial (24.00), } \\
\text { increase (21.93), } \\
\text { paediatric (I8.68), } \\
\text { department (18.6I), } \\
\text { psychosocial (I7.76), } \\
\text { professional (I7.36), } \\
\text { coverage (I7.|3), } \\
\text { benefit (I7.32), } \\
\text { psychologist (16.90), } \\
\text { pharmaceutical (I6.52), } \\
\text { physical therapist (I5.84), } \\
\text { society (I5.50), } \\
\text { government (I5.4I), }\end{array}$ & $\begin{array}{l}\text { product (I5.24), } \\
\text { state (I4.94), } \\
\text { country (14.85), } \\
\text { volunteer (I4.57), } \\
\text { company (14.15), } \\
\text { administration (I4.10), } \\
\text { necessary (I2.56), } \\
\text { financial resources (I I.56), bureaucracy (I I.37), } \\
\text { group (I0.95), } \\
\text { structure (I0.84), } \\
\text { hour (I0.64), } \\
\text { external (I0.63), } \\
\text { support (I0.50), } \\
\text { need (I0.50), } \\
\text { social (I0.33), } \\
\text { multidisciplinary (I0.28), } \\
\text { network (9.9I), } \\
\text { local ( } 9.25), \\
\text { authorize (8.95), } \\
\text { industry (8.60), } \\
\text { CountryUSA (8.I7), } \\
\text { TypeSocial worker (8.06), } \\
\text { Experience high (7.57), } \\
\text { politic (5.96) }\end{array}$ \\
\hline \multicolumn{3}{|c|}{ Examples of sentences of the cluster (ECUs, Elementary Context Units) } \\
\hline \multicolumn{3}{|c|}{$\begin{array}{l}\text { «So it would be very helpful if we could raise a small fund in order to provide this kind of support for some patients. We often have very good ideas } \\
\text { but we don't have money to implement them. I think we need more investment in order to get factors and to improve quality of living, and also get } \\
\text { prophylaxis» (Brazil, social worker, in team, level of experience 3). } \\
\text { «Everything can be improved, time is the main issue!» (UK, psychologist, in team, level of experience unassigned). } \\
\text { «Haematologists, paediatrics, social worker, psychologist, physiotherapists, orthopaedists, lab specialists, dentists: actually, we are in the Hospital, so } \\
\text { we have access to any specialty, which is also something that differs a bit. If you saw other state, the patients are helped in the Hemocenter and the } \\
\text { Hemocenter is not always linked to the Hospital» (Brazil, haematologist, in team, level of experience 3). } \\
\text { «There is always physiotherapy. There is someone like a social worker involved, because they work with people that are in a lot of need. The } \\
\text { government has everything for hemophilia, for the people in need. There are nurses aids and doctors, and there is the orthopaedist specialized in } \\
\text { haematrosis» (Brazil, haematologist, not in team, level of experience 2). }\end{array}$} \\
\hline
\end{tabular}

reactions that a prenatal diagnosis entails ("blame", "surprise", "panic", "deny" or "refuse", "guilt", "scare" and "shock" are all keywords of this cluster) and enacting adequate behaviours ("take care", "counsel", "suggest", "calm", “persuade").

Another evoked aspect is linked to genetic counselling and the HCPs' involvement in the decisionmaking process regarding reproductive options (eg, pregnancy, birth or abortion). Although this theme has already been addressed in the literature, ${ }^{6}$ this result stresses that this dynamic is especially referred to women, while a systemic view that includes the other family members or the role of men seems to be almost absent. According to HCPs interviewed, women play a primary role in this communication process: the word "woman" is followed by "mother", considering $\chi^{2}$.

The word "cancer" emerges as it evokes similar difficulties in communicating a breakpoint in personal and family life, a surprising and dramatic scenario, with reference to the chronic characteristic of the illness. 
Table 4 Keywords in order of $\chi^{2}$ and examples of sentences of the cluster no. 3

\begin{tabular}{|c|c|c|}
\hline \multicolumn{3}{|c|}{ Keywords of the cluster (in order of $\chi^{2}$ ) } \\
\hline $\begin{array}{l}\text { diagnose (30I.95), } \\
\text { family history (I38.84), } \\
\text { question (I35.30), } \\
\text { speak (I29.32), } \\
\text { carrier (I28.86), } \\
\text { explain (I26.87), } \\
\text { woman (I06.59), } \\
\text { mother (99.| } 3) \text {, } \\
\text { test (87.37), } \\
\text { pregnant (96.30), } \\
\text { inform (70.75), } \\
\text { birth (69.9I), } \\
\text { genetic counselling (67.4I), } \\
\text { daughter (55.43), } \\
\text { answer (52.7I), } \\
\text { react (50.45), } \\
\text { understand (48.7I), } \\
\text { pregnancy (47.25), } \\
\text { previous (45.70), } \\
\text { baby (45.52), } \\
\text { haemophiliac (45.23), } \\
\text { ideal (44.53), } \\
\text { family (42.8I), } \\
\text { discuss (40.85), } \\
\text { listen (38.|3), } \\
\text { blame (35.68), }\end{array}$ & $\begin{array}{l}\text { hear (35.6I), } \\
\text { genetic (34.25), } \\
\text { dependent (30.44), } \\
\text { know (28.56), } \\
\text { initial (28.0I), } \\
\text { abort (25.50), } \\
\text { father (23.20), } \\
\text { plan (23.18), } \\
\text { lack (22.9I), } \\
\text { confirmation (22.60), } \\
\text { chance (22.13), } \\
\text { shock (22.09), } \\
\text { take care (21.85), } \\
\text { prenatal (21.29), } \\
\text { moment (20.40), } \\
\text { step by step (20.29), } \\
\text { expect (19.45), } \\
\text { result (I8.32), } \\
\text { male (I7.22), } \\
\text { calm (I5.03), } \\
\text { cancer (15.03), } \\
\text { come back (15.03), } \\
\text { internet (14.16), } \\
\text { child (14.04), } \\
\text { prepare (13.58), } \\
\text { transmit (13.49), }\end{array}$ & $\begin{array}{l}\text { CountryAlgeria (I2.89), } \\
\text { anomaly (I2.73), } \\
\text { percent (I2.73), } \\
\text { circumcise (I2.73), } \\
\text { ask (I2.65), } \\
\text { counselling (I2.60), } \\
\text { decide (I } 2.47), \\
\text { son (I2.47), } \\
\text { mutation (II.64), } \\
\text { physician (II.47), } \\
\text { facility (II.35), } \\
\text { fault (I0.77), } \\
\text { coagulate (I0.77), } \\
\text { choice (I0.5I), } \\
\text { talk (I0.42), } \\
\text { tell (I0.28), } \\
\text { husband (9.68), } \\
\text { surprise (9.43), } \\
\text { scenario (9.43), } \\
\text { concept (9.39), } \\
\text { Country France (8.27), } \\
\text { examine (8.80), } \\
\text { panic (8.60), } \\
\text { adapt (7.9|), } \\
\text { drama (5.56) }\end{array}$ \\
\hline \multicolumn{3}{|c|}{ Examples of sentences of the cluster (ECUs, Elementary Context Units) } \\
\hline \multicolumn{3}{|c|}{$\begin{array}{l}\text { «As they grow into adulthood, I explain to them about inheritance and that any pregnancies resulting in a male born from carriers have a } 50 \% \text { of risk } \\
\text { looking at family history. I judge whether the mother can cope the decision. If they know she is a carrier, they are mentally prepared to accept } \\
\text { diagnosis but still need a lot of support from nurse and social worker in early stages» (UK, haematologist, in team, level of experience unassigned) } \\
\text { «Of course, we offer them all the diagnostic, but then the choose whether having a child or not is theirs. We can't generalize, there are different } \\
\text { reactions. The reaction of a mother known to be a carrier is different from the reaction of a family without a prior family history» (Italy, } \\
\text { haematologist, in team, level of experience 2) } \\
\text { «For a carrier woman, we have to establish if this requires a specific management as well as far as pregnancy is concerned, we have to check first, if } \\
\text { they are carriers or not. Women from hemophilic families are not all carriers. We have to explain what a carrier women diagnosis is, how it is done» } \\
\text { (France, haematologist, not in team, level of experience unassigned) } \\
\text { «lt happens sometimes. I don't take part in the counselling. The physician does that. They know that they are a carrier. Some take it easy and wait } \\
\text { and see. Others use all diagnostic options there are. It can be diagnosed whether the child is a carrier before the birth. I understand both» } \\
\text { (Germany, nurse, not in team, level of experience 3). }\end{array}$} \\
\hline
\end{tabular}

Finally, in this theme, cultural differences appear; the term "circumcision" is an example, suggesting that the diagnosis forces families to avoid, modify or experience a practice that is profoundly related to their cultural identity. HCPs and parents or patients with hemophilia in these phases have to negotiate two different languages.

Regarding the social and professional variables, French and Algerian HCPs are included in this cluster.

\section{Theme 4: considering the role of family dynamics}

This theme refers to the challenge of raising a child with hemophilia, with some specific relational dynamics and feelings such as worry, jealousy among siblings, and guilt.

HCPs report the mother's overprotection toward her child with hemophilia, who is viewed as always dependent. On the one hand, the first keywords underline the 
Table 5 Keywords in order of $\chi^{2}$ and examples of sentences of the cluster no. 4

\begin{tabular}{|c|c|c|}
\hline \multicolumn{3}{|c|}{ Keywords of the cluster (in order of $\chi^{2}$ ) } \\
\hline $\begin{array}{l}\text { child (I55.3I), } \\
\text { mother (I25.92), } \\
\text { parent (I08.85), } \\
\text { mum (85.36), } \\
\text { brother (8I.5I), } \\
\text { overprotect (75.02), } \\
\text { attention (72.29), } \\
\text { sibling (65.82), } \\
\text { boy (45.|7), } \\
\text { son (4I.95), } \\
\text { sister (40.84), } \\
\text { dad (39.60), } \\
\text { dependent (35.49), } \\
\text { mild (33.53), } \\
\text { guilt (33.03), } \\
\text { bad (29.98), } \\
\text { father (23.|4), } \\
\text { jealousy (22.72), } \\
\text { girl (22.39), } \\
\text { learn (I8.54), } \\
\text { blame (I8.44), } \\
\text { normal child (I8.27), } \\
\text { moderate (I8.27), } \\
\text { old (I7.43), } \\
\text { cultural (I6.3I), } \\
\text { arm (I5.40), }\end{array}$ & 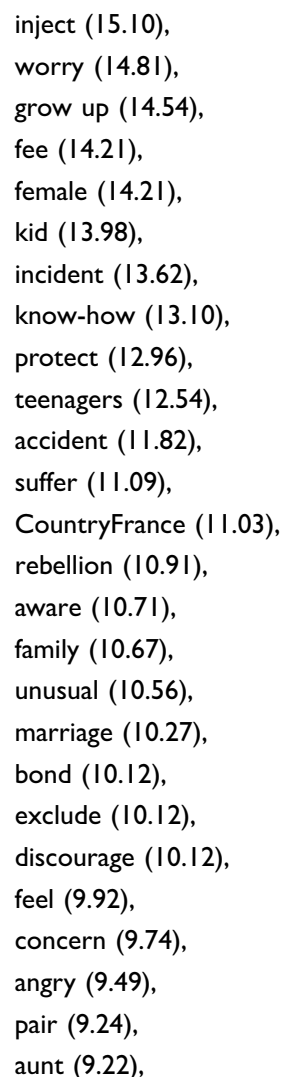 & $\begin{array}{l}\text { watch }(9.17), \\
\text { chance (9.12), } \\
\text { camp ( } 9.11) \text {, } \\
\text { careful (9.08), } \\
\text { carrier (9.95), } \\
\text { risk (8.9I), } \\
\text { adapt (8.9I), } \\
\text { hurt (8.8I), } \\
\text { play (8.75), } \\
\text { different (8.04), } \\
\text { generation (7.57), } \\
\text { live with illness (7.27), } \\
\text { story (7.II), } \\
\text { complication (6.85), } \\
\text { impact (6.79), } \\
\text { imagine (6.76), } \\
\text { vein (6.39), } \\
\text { Type Nurse (6.36), } \\
\text { danger (6.3I), } \\
\text { behaviour (6.02), } \\
\text { encourage (5.3I), } \\
\text { baby (5.02), } \\
\text { calm (5.00), } \\
\text { ignorance (4.9I), } \\
\text { conflict (4.49), } \\
\text { confuse (4.43) }\end{array}$ \\
\hline \multicolumn{3}{|c|}{ Examples of sentences of the cluster (ECUs, Elementary Context Units) } \\
\hline \multicolumn{3}{|c|}{$\begin{array}{l}\text { «There is a high level of couples splitting because they feel guilty... the parents, the father's family blame the mother because she had a child with } \\
\text { a problem. There are couples who faces it quite well» (Brazil, nurse, in team, level of experience 3) } \\
\text { « It is a big impact. In a family with a PWH everything is focused on the child with hemophilia. For that reason, we do tell the parents to be careful } \\
\text { with the brother or sister, because a lot of the parents tend to be overprotective with the child with hemophilia» (France, nurse, in team, level of } \\
\text { experience 2) } \\
\text { « I work both with children and their mothers, who feel guilty and therefore give too many attentions to their sons/much more than the other } \\
\text { mothers). We have to teach these mothers not to be overprotective, but to let their children do whatever they want, maybe talking with them and } \\
\text { finding compromises» (Italy, physiotherapist, in team, level of experience unassigned) } \\
\text { «We do our best to manage his anger and provide him with the proper treatment. I will never forget the case of a child who was } 9 \text { years old, his } \\
\text { parents were separated, the child lived with his mother who got remarried and in this step-dad wasn't supportive with his hemophilia» (Algeria, } \\
\text { haematologist, in team, level of experience 3) }\end{array}$} \\
\hline
\end{tabular}

close relationship between mother and child; on the other hand, they highlight some potential problems with the illness-free siblings.

The unfulfilled expectations of having a healthy child fills the parents with discouragement and it seems that also marriage dynamics are undermined.

It is a topic investigated by literature above all from the patient's or family's point of view, less from that of the HCPs. ${ }^{41}$

HCPs portray parents as confused or insecure people while the word "grandparents" is close to the word "ignorance," suggesting a lack of involvement of other family members. Family is not considered as a resource for the development of gradual patient autonomy, but as a difficult challenge or as an obstacle to deal with due to its overprotection toward the sick child: there are no positive words, only negative or neutral ones.

Summer camp activities, where kids can do many different activities and learn to self-infuse, are evoked as important opportunities that help to give children more independence. However, HCPs interventions are not really 
Table 6 Keywords in order of $\chi^{2}$ and examples of sentences of the cluster no. 5

\begin{tabular}{|c|c|c|}
\hline \multicolumn{3}{|c|}{ Keywords of the cluster (in order of $\chi^{2}$ ) } \\
\hline $\begin{array}{l}\text { school (202.09), } \\
\text { sport (190.97), } \\
\text { start (150.18), } \\
\text { teenagers (100.57), } \\
\text { kids (92.43), } \\
\text { prophylaxis (80.75), } \\
\text { play (76.95), } \\
\text { age (75.99), } \\
\text { young (7I.47), } \\
\text { football (69.30), } \\
\text { stage (63.72), } \\
\text { walk (49.55), } \\
\text { crisis (45.08), } \\
\text { limit (44.02), } \\
\text { older (42.13), } \\
\text { adolescent (40.34), } \\
\text { joint (33.73), } \\
\text { puberty (37.62), } \\
\text { physical education (36.24), } \\
\text { impact (35.13), } \\
\text { independent (34.9I), } \\
\text { bleedings (34.49), } \\
\text { period (34.39), } \\
\text { soccer (34.18), } \\
\text { haemorrhage (32.34), } \\
\text { perception (3I.23), } \\
\text { self-injection (3I.02), }\end{array}$ & $\begin{array}{l}\text { haemarthrosis (30.85), } \\
\text { infuse (30.8I), } \\
\text { bad (26.6I), } \\
\text { transition (26.43), } \\
\text { hockey (23.34), } \\
\text { friend (23.I5), } \\
\text { miss (20.79), } \\
\text { love (20.54), } \\
\text { life (20.25), } \\
\text { contact (20.2I), } \\
\text { move (I9.96), } \\
\text { worry (I9.49), } \\
\text { activity (I8.76), } \\
\text { climb (I8.09), } \\
\text { young adults (I8.09), } \\
\text { learn (I7.96), } \\
\text { childhood (I6.80), } \\
\text { huge (I6.07), } \\
\text { weight (I6.06), } \\
\text { cope (I5.45), } \\
\text { parent (I5.33), } \\
\text { severe (I4.87), } \\
\text { first year (I4.68), } \\
\text { muscle (I4.47), } \\
\text { lift (I3.0I), } \\
\text { afraid (I2.56), }\end{array}$ & $\begin{array}{l}\text { crucial (I } 2.08), \\
\text { teach (I2.03), } \\
\text { wheelchair (I2.03), } \\
\text { strong (II.87), } \\
\text { college (II.87), } \\
\text { music (II.67), } \\
\text { careful (II.56), } \\
\text { accident (II.I6), } \\
\text { pain (I0.36), } \\
\text { trip (I0.36), } \\
\text { hospitalization (I0.34), } \\
\text { trouble (I0.34), } \\
\text { regret (I0.I3), } \\
\text { deform (I0.I3), } \\
\text { girlfriend (I0.02), } \\
\text { prevent ( } 9.3 \mid \text {, } \\
\text { relationships (8.94), } \\
\text { frustrate (8.55), } \\
\text { encourage (8.44), } \\
\text { prohibit (8.24), } \\
\text { compete (8.24), } \\
\text { baseball (8.24), } \\
\text { rebellion (7.50), } \\
\text { HIV (6.83), } \\
\text { trauma (6.28) }\end{array}$ \\
\hline \multicolumn{3}{|c|}{ Examples of sentences of the cluster (ECUs, Elementary Context Units) } \\
\hline \multicolumn{3}{|c|}{$\begin{array}{l}\text { «The child grows up and the teenager is probably a critical stage then the child can be frustratedat notbeing able to do the same sports as other } \\
\text { teenagers do, this is the high school period corresponding to the teenage years. It is generally the time when they want to stop because they feel } \\
\text { well, sometimes with the help of prophylaxis, and they don't understand why they have to carry on» (France, nurse, in team, level of experience I) } \\
\text { « It's the period when the child is teenager and sometimes he doesn't accept his treatment like he used to; when he is young the mum is managing } \\
\text { everything and then he is a teenager; for some of them, they don't have the compliance I thought they would have» (France, haematologist, in team, } \\
\text { level of experience 3) } \\
\text { « They start to have some realization that they are different from other kids and how to deal with that difference when they go off to school. Sure } \\
\text { when they get to be teenagers and they get to be a little bit more independent and they need to be more independent about also managing their } \\
\text { disease and certainly when they start to have a girlfriends, how to tell it to the girlfriends and their friends?» (USA, nurse, in team, level of } \\
\text { experience 3) } \\
\text { «Hemophilia has many repercussions on their life: from not being able to go to school, to participating in sports and later on in life the concern of } \\
\text { getting married and having kids. For the adults there is the professional absenteeism or in some cases they don't get to finish college. They can't play } \\
\text { all kinds of sports, they can't be as outdoorsy as they want » (Algeria, haematologist, in team, level of experience 3) }\end{array}$} \\
\hline
\end{tabular}

mentioned: HCPs are more like observers rather than being directly involved, with the exception of the role of calming and encouraging the family.

This theme is particularly evoked by some sub-groups of participants: French HCPs and nurses especially contribute to the definition of this cluster.

\section{Theme 5: coping with adolescent patients}

In this theme, the smallest, the image of the young patients is specifically described. It is a theme filled with emotional connotations regarding the transition stage from teenager to young adulthood, with its peculiarities and needs. It represents an intense moment for HCPs. They consider the feelings of this 
age group very carefully, together with the main fears and worries concerning body deformity, pain, death, HIV, wheelchair use, and hospitalisation. Prophylaxis seems to have a special role in the patients' life. On the one hand, it allows an almost normal quality of life, while on the other, it requires a considerable amount of personal commitment by the growing patient, entailing a psychological burden.

Young patients are imagined in their context (especially at school or at work) and involved in relationships (ie, sentimental ones), with attention to frustration because of hemophilia, dealing with the typical phases of youth, such as love and sexuality. ${ }^{42}$

Adolescents need independence and autonomy but have also to come to terms with limitations regarding some physical activities (eg, contact sports), or deal with disclosure of their hemophilia to peers. One of the most important aspects that has an impact on the health care staff is the "crisis" during this age phase due to rebellion, anger, prohibition, hurt, regret. Medical and psychological literature has noted a lack of compliance during adolescence in the case of chronic diseases and a difficult doctor-patient relationship. ${ }^{19}$ In this study, instead, HCPs seem to be empathetically close to adolescents: they represent a challenge, but also a vital element of their professional activities. The patients in this theme are problematic, but also active and dynamic; they are represented as being full of dreams and hopes compared to adult patients, who are described as frustrated, resigned and unlucky (see cluster 1).

Similar to what has been noted with regard to adult patients in cluster 1 , this theme also seems to be transversal to all participants, regardless of the social and professional variables considered: no sub-group of participants significantly contributes to the construction of this cluster.

\section{Factorial space and variables' positioning}

These thematic clusters are placed into a multidimensional space defined by three main factors, each consisting of two polarities. The intersection of the first two factors is graphically illustrated in Figure 1 and described below.

The first factor (x-axis in Figure 1) opposes what we named "Focus on patients' context" on the one pole to "Focus on HCPs' context" on the other pole; in other words, it relates the focus on the patients and their relationships within their local context (on the negative semi-axis, where clusters 4 and 5 are placed) to the focus on the other stakeholders involved and their needs within a more global network (on the positive semi-axis, where the cluster 2 is placed).

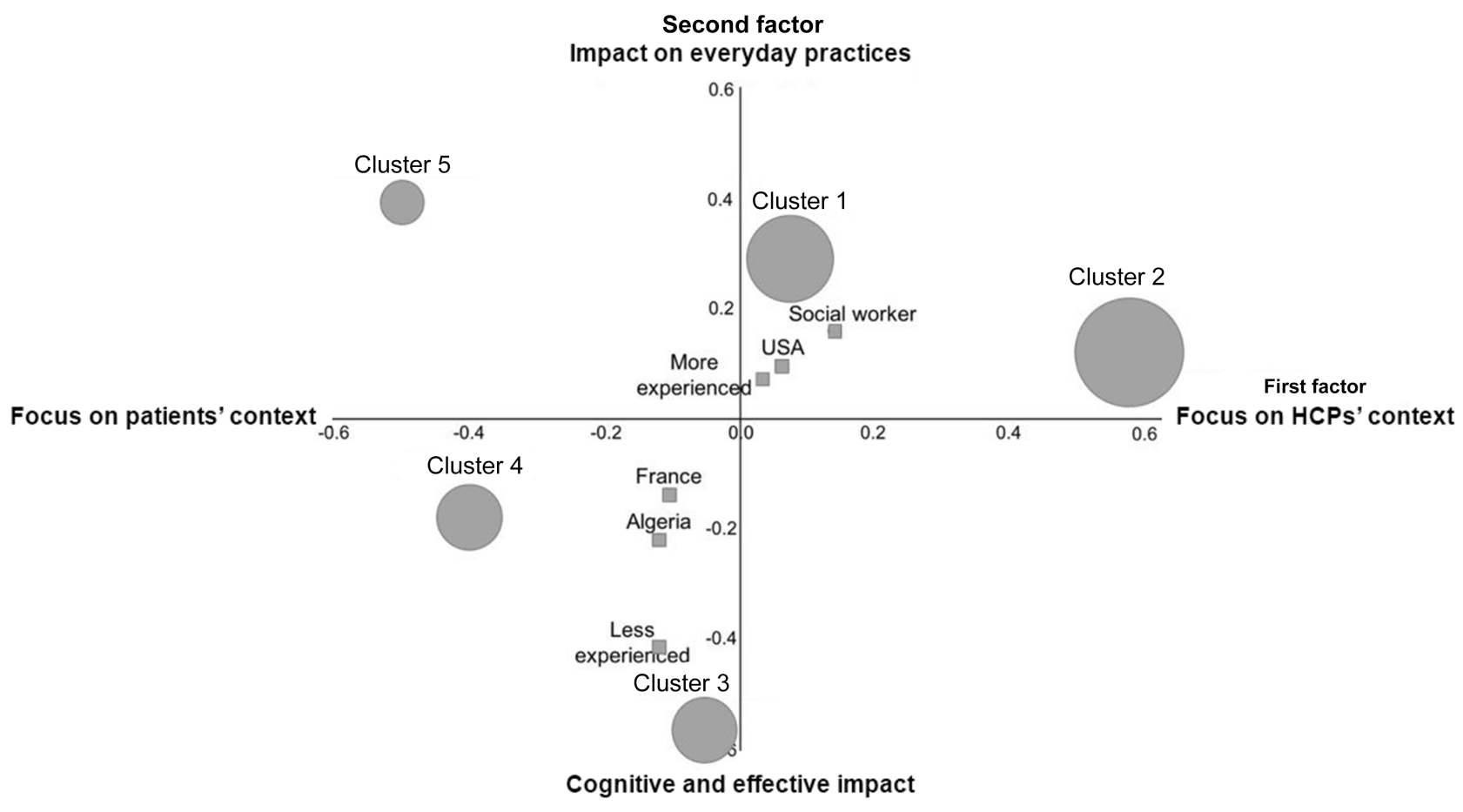

Figure I Factorial plane: First (x-axis) and second (y-axis) factors.

Notes: The points represent the clusters and the point's size is proportional to the value of their absolute contribution; the squares represent the positioning of the modes of the supplementary variables on the factorial plane; only those modes with a test-value higher than 1.96, in absolute value, are displayed.

Abbreviation: HCPs, health care professionals. 
The dichotomy between what we called "Cognitive and affective impact" on the one pole and "Impact on everyday practices" on the other characterises the second factor (y-axis in Figure 1). In particular, it is based on the opposition between the emotional reactions to hemophilia and the efforts to understand every aspect of it (on the negative semi-axis, where clusters 3 and 4 are placed), and the limitations imposed by the disease and the effects of the treatment on the patients' and HCPs' life (on the positive semi-axis, where clusters 1, 2 and 5 are placed).

With reference to variables, the modes "USA," "social worker," and "more experienced HCP," are placed in the quadrant made by the intersection of the poles "Focus on HCPs' context" and "Impact on everyday practices," near clusters 1 and 2. Concerning the USA, it can be due to its private health care system that may lead to a greater impact of illness on patients' daily lives and worries, as already observed in a previous study on hemophilic patients from the USA and UK. ${ }^{38}$ This positioning also interests social workers who, for the specificity of their work, are engaged in the construction of networks for patient inclusion in the social context, and the more experienced HCPs, as they may be more able to notice the influence that the local legislative and economic system has on hemophilia care. On the opposite quadrant, at the intersection of the poles "Focus on patients' context" and "Cognitive and affective impact," close to clusters 3 and 4, there are the modalities "France," "Algeria," and the respondents with fewer years of experience. This result suggests that respondents from this Francophone area paid greater attention to family dynamics and women's counseling, and also that the less experienced HCPs may be more sensitive to such issues and interested in improving communicative strategies.

All the other modalities of the variables are close to the origin, as they share the entire argument without particularly stressing one or more issues.

\section{Discussion}

Understanding the HCPs' viewpoint about their subjective work experience is a relatively new research topic, largely underexplored in the scientific literature. However, it is highly relevant for maintaining well-being, improving relationships and communication with patients, enhancing health service organisation, and identifying problems and perceived resources. ${ }^{10}$

In this research, we have focused on the experiences of HCPs working with hemophilia, a rare chronic illness, by adopting a psychosocial and cross-cultural perspective. In particular, we aimed at identifying the common subjective experience that substantiates the HCPs' work practices, as well as at investigating whether and how these models vary according to different HCPs' professional and social characteristics. For this purpose, we interviewed HCPs from seven different countries worldwide (both with developing and developed economy) and with different medical specialities and years of experience.

The results showed five dominant themes through which HCPs spoke of their work, identifying the main challenges to be dealt with in their everyday practice: caring for impaired adult patients, as well as related threats/experiences of stress and burnout; handling policies, resources and stakeholders, thus considering the economic and social costs of hemophilia, while forgetting patients and their needs; providing counselling about diagnosis and reproductive choices, which is perceived as a demanding task that involves mainly women; considering the role of family dynamics, more for their dysfunctional patterns than for their effective configurations; coping with adolescent patients, who represent both a challenge and a vital element thanks to the variety of treatment options and the more favourable treatment prospects as compared with the past.

These challenges are positioned along two main semantic dimensions through which the discourse on the HCPs' work experiences is organised: the "Focus on patients' context" vs the "Focus on HCPs' context"; the "Cognitive and affective impact" vs the "Impact on everyday practices".

Overall, these dimensions account for the complexity of working within a chronic disease such as hemophilia. On the one hand, the HCPs' side (in terms of working environment, disease management and impact on their life and work practices) emphasizes the need for the HCPs to maintain their well-being, to master specific medical skills but also crossprofessional non-technical skills (eg, working in a team), and of deeply knowing their workplace and the wider health care system with its policies and stakeholders. On the other hand, considering the patients' side (in terms of caring network, home management in everyday life and emotional reactions to the disease) results in highlighting other competences that HCPs should have; these are mainly cross-professional nontechnical skills related to communication, counselling and long-term availability. In this case, the well-being to be preserved is that of the patients and their caregivers, guaranteeing them optimal care and a better quality of life. Thus, the role of HCPs is to guide patients towards these goals. 
Although further research is needed to provide a more precise interpretation of the role of the social and professional variables considered, contrary to our expectations, the discourse on the topic under examination appears to be widely shared by all the professionals interviewed, almost regardless of the different variables considered. This result is particularly surprising as regards the respondents' country of origin, since we included countries with both developing and developed economies; it highlights how the challenges that emerged are considered to be transversal to all work contexts, regardless their specificities.

\section{Strengths and limitations}

The strength of this research is the innovative opportunity to know what is common in the narrative of different HCPs in the field of hemophilia, paying attention to the implicit theories that guide the professional practice, starting from assumption that this consensual universe is not a source of bias or error, but is the world of meanings and experiences that affect the professional practice.

The specific methodology adopted for data collection (not objective but self-report) and the type of data analysis (qualitative but with a help of software for thematic maps showing the common implicit themes and also the role of some variables) are also a strengths.

A weak point is the composition of participants: other studies are necessary to deep the role of social variables in the common representations.

\section{Implications for future research or clinical practice}

As for the applied implications, the outcomes of the study thus provide an opportunity to develop the area of those intrinsic roles that are not medical expertise in the core curriculum of HCPs who work with chronic illnesses by focusing on cross-professional competences and by improving a comprehensive care model for hemophilia patients. In this regard, it is possible to identify key areas of interest, which are strategic for conducting further research, investing resources, and planning training within a continuing education process that is not based on performances, but task-oriented, identifying the needs of all HCPs. Teunissen and Bok, ${ }^{43}$ in this direction, have shown how there is an increasing need for continuing education, which starts from a reflection on everyday practices and self-theories and not from biomedical knowledge learned in courses.

In particular, the main issues that we consider relevant for HCPs working with hemophilia are:

- reflection about adult patients' perception, with a focus on the resources and not only on the difficulties;

- competences of building a network based on job engagement; human resource management skills; communication skills with colleagues;

- ability to establish a good and supportive relationship with patients and caregivers, active listening skills, and customers' orientation;

- knowledge of family dynamics and relational systemic psychological theories;

- knowledge of the main characteristics of teenagers' transition from a psychosocial point of view and negotiation strategies of communication to improve both patient compliance and autonomy.

Increased awareness of these issues can improve the quality of care, trigger greater attention to the aspect of multidisciplinary teams and teamwork and reduce the incidence of burnout and psycho-emotional difficulties. ${ }^{44}$

\section{Ethics approval and informed consent}

The ethics committees responsible for each country involved and the HERO International Advisory Board approved the study. Written informed consent was obtained from the health care professionals for their anonymized information to be published in this article.

\section{Acknowledgments}

We thank Professor Alfonso Iorio, McMaster University, for his support and for allowing us to work on the interviews collected within the Haemophilia Experience, Results and Opportunities (HERO) Initiative. This work was supported by the McMaster University (collaborative research agreement between McMaster University and Bologna University, number 10-850716; total funding 10,000 CAD) as part of an unrestricted research grant from Novo Nordisk for the Haemophilia Experience Results and Opportunities (HERO) initiative. 


\section{Author contributions}

Silvia Potì, Laura Palareti, and Frederica Cassis researched the literature and conceived the study. Frederica Cassis was involved in protocol development, gaining ethical approval, and conducting patient recruitment. Silvia Potì and Laura Palareti were involved in the data analysis. Silvia Potì, Laura Palareti and Sonia Brondi wrote the first draft of the manuscript. All authors contributed to data analysis, drafting and revising the article, gave final approval of the version to be published, and agree to be accountable for all aspects of the work.

\section{Disclosure}

Frederica RMY Cassis received honoraria from Novo Nordisk for oral presentations in meetings and symposium; Silvia Potì reports grants from Novo Nordisk, during the conduct of the study; Laura Palareti reports grants from Novo Nordisk, outside the submitted work. The authors report no other conflicts of interest in this work.

\section{References}

1. Taylor G. Challenges for social work in hemophilia care. Health Soc Work. 2004;29:149-152. doi:10.1093/hsw/29.2.149

2. Doise W. European Monographs in Social Psychology. Levels of Explanation in Social Psychology. New York, NY, US: Cambridge University Press; 1986.

3. Wallas JE, Leamire JB, Ghali WA. Physician wellness: a missing quality indicator. Lancet. 2009;374:1714-1721. doi:10.1016/S01406736(09)61424-0

4. Haas LJ, Leiser JP, Magill MK, Sanyel ON. Management of the difficult patient. Am Fam Physician. 2005;72:2063-2068.

5. Shapiro J, Astin J, Shapiro SL, Robitshek D, Shapiro DH. Coping with loss of control in the practice of medicine. Family Syst Health. 2011;29:15-28. doi:10.1037/a0022921

6. Serour M, Othman HA, Khalifah GA. Difficult patients or difficult doctors: an analysis of problematic consultations. Eur J Gen Md. 2009;6:1304-3889. doi:10.29333/ejgm/82646

7. Rolstad EB. Social worker perceptions and observations regarding men's management of hemophilia and use of community-based support. Health Soc Work. 2015;40:239-244.

8. Kennedy JS. Physicians' feelings about themselves and their patients. $J$ Am Med Assoc. 2002;287:1113-1114.

9. Vegni E, Leoni D, Biasoli C, Moja EA. Difficult encounters with a hemophilic patient: the inner perspective of physicians. $J$ Health Psychol. 2014;19:1499-1507. doi:10.1177/1359105313493813

10. Aase M, Nordrehaug JE, Malterud K. "If you cannot tolerate that risk, you should never become a physician": A qualitative study about existential experiences among physicians. J Med Ethics. 2008;34:767-771. doi:10.1136/jme.2007.023275

11. Breuner CC, Moreno MA. Approaches to the difficult patient/parent encounter. Pediatrics. 2011;127:163-169. doi:10.1542/peds.20100072

12. Triemstra AHM, Van der Ploeg HM, Smit C, Briet E, Ader HJ, Rosendaal FR. Well-being of haemophilia patients: a model for direct and indirect effects of medical parameters on the physical and psychosocial functioning. Soc Sci Med. 1998;47:581-593.
13. Rodriguez-Merchan EC. Aspects of current management: orthopaedic surgery in haemophilia. Haemophilia. 2012;18:8-16. doi:10.1111/ j.1365-2516.2011.02544.x

14. Baker JR, Crudder SO, Riske B, Bias V, Forsberg A. A model for a regional system of care to promote the health and well-being of people with rare chronic genetic disorders. Am J Public Health. 2005;95:1910-1916. doi:10.2105/AJPH.2004.051318

15. Street A. Developing models of haemophilia care. Haemophilia. 2012;18:89-93. doi:10.1111/j.1365-2516.2012.02876.x

16. WFH. Abstract of the WFH 2014 World Congress, May $11-15$, Melbourne, Australia. Haemophilia. 2004;20:1-186.

17. Potì S, Palareti L, Emiliani F, Rodorigo G, Valdrè L. The subjective experience of living with haemophilia in the transition from early adolescence to young adulthood: the effect of age and the therapeutic regimen. International Journal of Adolescence and Youth. 2018;23:133-144. doi:10.1080/02673843.2017.1299017

18. Kyngas H, Rissanen M. Support as a crucial predictor of good compliance of adolescents with a chronic disease. J Clin Nurs. 2001;10:767-774.

19. Petrini P, Seuser A. Haemophilia care in adolescents - compliance and lifestyle issues. Haemophilia. 2009;15:15-19. doi:10.1111/ j.1365-2516.2008.01948.x

20. Kand HS, Kim WO, Jeong Y, Kim SY, Yoo KY. Effect of a self-help program for mothers of hemophilic children in Korea. Haemophilia. 2002;18:892-897.

21. Mulders G, De Wee EM, Vahedi Nikbakht-Van de Sande MCVM, Kruip MJ, Elfrink EJ, Leebeek FW. E-learning improves knowledge and practical skills in haemophilia patients on home treatment: a randomized controlled trial. Haemophilia. 2002;18:693-698. doi:10.1111/j.1365-2516.2012.02786.x

22. Arranz P, Rodriguez-Merchan EC, Hernández-Navarro F. Burnout syndrome in haemophilia staff. In: Rodriguez-Merchan EC, Goddard NJ, Lee CA, editors. Musculoskeletal Aspects of Haemophilia. Oxford: Blackwell Science Ltd; 2008:212-217.

23. Brown LK, Schultz JR, Forsberg AD, King G, Kocik SM, Butler RB. Predictors of retention among HIV/hemophilia health care professionals. Gen Hosp Psychiatry. 2002;24:48-54.

24. Brown LK, Stermock AC, Ford HH, Geary M. Emotional reactions of haemophilia health care providers. Haemophilia. 1999;5:127-131.

25. Dyrbye LN, Shanafelt TD, Sinsky CA, et al. Burnout among health care professionals: A call to explore and address this underrecognized threat to safe, high-quality care. NAM Perspectives. 2017. doi:10.31478/201707b

26. Mazzoni D, Marchetti L, Albanesi C, Cicognani E. L'uso di T-LAB in psicologia della salute. Una rassegna della letteratura [The use of T-LAB in Health Psychology. A literature review]. Psicologia della Salute. 2008;2:91-114.[in italian].

27. Caputo A. Exploring quality of life in Italian patients with rare disease: A computer-aided content analysis of illness stories. Psychol Health Med. 2014;19:211 221. doi:10.1080/ 13548506.2013.793372

28. Montali L, Monica C, Riva P, Cipriani R. Conflicting representations of pain: A qualitative analysis of health care professionals' discourse. Pain Med. 2011;12:1585-1593. doi:10.1111/j.1526-4637.2011.01252.x

29. Emiliani F, Bertocchi S, Potì S, Palareti L. Process of Normalization in families with children affected by congenital haemorragic diseases. Qual Health Res. 2011;21(12):1667-1678. doi:10.1177/1049732311417456

30. Cassis FR, Querol F, Forsyth A, Iorio A, Hero international Advisory Board. Psychosocial aspects of haemophilia: a systematic review of methodologies and findings. Haemophilia. 2012;18(3):e101-14. doi:10.1111/j.1365-2516.2011.02683.x.

31. Palareti L, Potì S, Cassis F, Emiliani F, Matino D, Iorio A. Shared topics on the experience of people with haemophilia living in the UK and the USA and the influence of individual and contextual variables. Int J Qual Stud Health Well-Being. 2015;10:28915. doi:10.3402/qhw. v10.28915 
32. Lancia F. Strumenti per L'analisi Dei Testi [Tools for Textual Analysis]. Rome: Franco Angeli; 2004. [in italian].

33. Potì S, Emiliani F, Palareti L. Subjective experience of illness among adolescents and young adults with diabetes: a qualitative research study. J Patient Exp. 2018;5(2):140-146. doi:10.1177/ 2374373517738234

34. Nugent D, Kalnins W, Querol F, et al. Haemophilia Experiences, Results and Opportunities (HERO) study: treatment-related characteristics of the population. Haemophilia. 2015;21(1):e26-e38. doi:10.1111/hae. 12545

35. Ruggieri R, Pozzi M, Ripamonti S. Italian family business cultures involved in the generational change. Eur J Psychol. 2014;10:79-103. doi:10.5964/ejop.v10i1.625

36. Åsbring $\mathrm{P}$, Närvänen AL. Ideal versus reality: physicians perspectives on patients with chronic fatigue syndrome (CFS) and fibromyalgia. Soc Sci Med. 2003;57:711-720. doi:10.1016/S0277-9536(02)00420-3

37. Crutcher JE, Bass MJ. The difficult patient and the troubled physician. J Family Pract. 1980;11:933-938.
38. Gorlin R, Zucker HD. Physicians' reactions to patients. A key to teaching humanistic medicine. N Engl J Med. 1983;308:1059-1063. doi:10.1056/NEJM198305053081804

39. Meier DE, Back AL, Morrison RS. The inner life of physicians and care of the seriously ill. J Am Med Assoc. 2001;286:3007-3014.

40. Stone L. Blame, shame and hopelessness: medically unexplained symptoms and the 'heart sink' experience. Aust Fam Physician. 2014;43:191-195.

41. Goldstein G, Kenet G. The impact of chronic disease on the family. Hemophilia. 2002;8:461-465. doi:10.1046/j.1365-2516.2002.00642.x

42. Boyce MM. Chronic illness in adolescence. Adolescence. 1997;33:927-939.

43. Teunissen PW, Bok HGJ. Believing is seeing: how people's beliefs influence goals, emotions and behavior. Med Educ. 2013;47:1064-1072. doi:10.1111/medu.12228

44. Vegni E, Visioli S, Moja EA. When talking to the patient is difficult: the physician's perspective. Commun Med. 2005;2:69-76. doi:10.1515/come.2005.2.1.69
Journal of Multidisciplinary Healthcare

\section{Publish your work in this journal}

The Journal of Multidisciplinary Healthcare is an international, peerreviewed open-access journal that aims to represent and publish research in healthcare areas delivered by practitioners of different disciplines. This includes studies and reviews conducted by multidisciplinary teams as well as research which evaluates the results or conduct of such teams or healthcare processes in general. The journal covers a very wide range of areas and welcomes submissions from practitioners at all levels, from all over the world. The manuscript management system is completely online and includes a very quick and fair peer-review system. Visit http://www.dovepress.com/testimonials. php to read real quotes from published authors. 